\title{
Cost-effectiveness analysis of combining traditional Chinese medicine in the treatment of hypertension: compound Apocynum tablets combined with Nifedipine sustained-release tablets vs Nifedipine sustained-release tablets alone
}

\author{
Qian $\mathrm{Xu}^{1+}$, Nan Yang ${ }^{1+}$, Shuang Feng ${ }^{1}$, Jianfei Guo ${ }^{2}$, Qi-bing $\mathrm{Li}^{3^{3 *}}$ and Ming Hu${ }^{1 *}$ (D)
}

\begin{abstract}
Background: We evaluated the long-term cost-effectiveness of antihypertensive traditional Chinese medicines (TCMs) and to compare the cost-effectiveness of a combined treatment consisting of compound Apocynum tablets and Nifedipine sustained-release tablets with the cost-effectiveness of treatment with Nifedipine sustained-release tablets alone.

Methods: A Markov model was used to simulate the potential incremental cost-effectiveness per quality-adjusted life year (QALY) to be gained from compound Apocynum tablets and Nifedipine sustained-release tablets compared with Nifedipine sustained-release tablets alone. Model parameter estimates were informed by previously published studies. The direct medical costs of outpatients with hypertension were estimated from the health care provider's perspective. A 5\% annual discount rate was applied to both costs and QALYs.

Results: TCMs combined with Nifedipine sustained-release tablets group generated a total 20-year cost of 11,517.94 RMB (US \$1739.87), whereas Nifedipine sustained-release tablets alone group resulted in a 20-year cost of 7253.71 RMB (US \$1095.73). TCMs combined with Nifedipine sustained-release tablets group resulted in a generation of 12.69 QALYs, whereas Nifedipine sustained-release tablets alone group resulted in 12.50. The incremental cost-utility ratio was 22 , 443.32 RMB (US \$3390.23) per QALY. Considering the threshold of 1 GDP per capita in China in 2018 (US \$9764.95), the combination of compound Apocynum tablets and Nifedipine sustained-release tablets was a cost-effective strategy. One-way and probabilistic sensitivity analysis showed unchanged results over an acceptable range.

(Continued on next page)
\end{abstract}

\footnotetext{
* Correspondence: qibingliu@aliyun.com; huming@scu.edu.cn

${ }^{\dagger}$ Qian Xu and Nan Yang contributed equally to this work and are co-first authors.

${ }^{3}$ Department of Pharmacology, School of Pharmaceutical Science, Hainan Medical University, Haikou, Hainan, China

${ }^{1}$ West China School of Pharmacy Sichuan University, 17, Renmin South Road, 3rd Section, Chengdu 610041, Sichuan, China

Full list of author information is available at the end of the article
}

C C The Author(s). 2020 Open Access This article is licensed under a Creative Commons Attribution 4.0 International License, which permits use, sharing, adaptation, distribution and reproduction in any medium or format, as long as you give appropriate credit to the original author(s) and the source, provide a link to the Creative Commons licence, and indicate if changes were made. The images or other third party material in this article are included in the article's Creative Commons licence, unless indicated otherwise in a credit line to the material. If material is not included in the article's Creative Commons licence and your intended use is not permitted by statutory regulation or exceeds the permitted use, you will need to obtain permission directly from the copyright holder. To view a copy of this licence, visit http://creativecommons.org/licenses/by/4.0/ The Creative Commons Public Domain Dedication waiver (http://creativecommons.org/publicdomain/zero/1.0/) applies to the data made available in this article, unless otherwise stated in a credit line to the data. 
(Continued from previous page)

Conclusions: Combining Traditional Chinese Medicines with chemical medicines is more cost-effective strategy in the treatment of hypertension.

Keywords: TCMs, Compound Apocynum tablets, Nifedipine sustained-release tablets, Blood pressure variability, Markov model, Cost-effectiveness analysis

\section{Background}

Hypertension is one of the most common chronic diseases that threatens human health, and it is also the major risk factor for cardiovascular diseases [1]. It has been reported [2] that 2 million people die of hypertension every year, $71 \%$ of the deaths caused by stroke are

related to hypertension, and $53 \%$ of the deaths caused by coronary atherosclerotic heart disease are related to hypertension in China. Good blood pressure control is expected to avoid 350,000 to 600,000 deaths between 2016 and 2030 [3]. In 2015, the per capita medical expenses (outpatient and hospitalization expenses) of hypertension in China were $\$ 1123.88$ per year, and the per capita medical expenses (including outpatient and hospitalization expenses) of patients with four primary hypertension complications were $\$ 1587.16$ per year [4].

With the progress of disease recognition, the goal of hypertension treatment has gradually changed from controlling blood pressure to improving complications related to target organ injury and improving blood pressure variability to reduce the long-term risk of cardiovascular (CVD) [5]. Yikona et al. found that an increase in blood pressure variability (BPV) is related to the occurrence, development and severity of cardiovascular and renal injury [6]. An increase in BPV in $24 \mathrm{~h}$ was related to the incidence and mortality of cardiovascular events $[7,8]$. Standard deviations (SDs) and coefficient of variations (CVs) are often used as indicators of BPV in the clinic [9]. The results of a post-analysis of a largescale intervention trial for hypertension in 2010 showed that BPV measured during the consultation period had a strong predictive value for cardiovascular morbidity [9]. Even in some cases, the correlation between BPV and cardiovascular incidence is stronger than the relationship between mean blood pressure and BPV [10].

Previous studies have found that traditional Chinese medicines (TCMs) not only have an obvious effect on the improvement of BPV, with the characteristics of stabilize blood pressure and better control of 24-h ambulatory blood pressure but also reduce adverse events and protect target organs, including the heart, brain and kidney [11-15]. Previous studies indicated that TCMs (e.g., the liuwei dihuang pill and tianma gouteng yin) were effective and safe for primary hypertension when compared with conventional treatments (e.g., diuretics, beta-blockers, calcium-channel blockers, and
ACE inhibitors) [16, 17]. According to the Guidelines for the Rational Use of Hypertensive Drugs in China and the Chinese expert consensus document on antihypertensive therapy with single-pill combination [18, 19], it is indicated that two or more drugs should be used together. Chemical

antihypertensive drugs combined with traditional Chinese medicine with different antihypertensive mechanisms can achieve blood pressure and reduce adverse events.

Compound Apocynum tablets are composed of Apocynum, Stephania tetrandra, Chrysanthemum indicum, etc. [20]. Some studies have shown that Apocynum extract can reduce blood pressure by enhancing the production and release of nitric oxide [21] or improving renal function. In addition, Compound Apocynum extract can be used for the treatment of hypertension, and it protects liver and decreases anxiety and depression [21, 22].

Most of the efficacy, safety and economic evaluations of antihypertensive drugs used systolic blood pressure (SBP) or diastolic blood pressure (DBP) as the main clinical indicator, and there is less research in which blood pressure variability is the main indicator. Therefore, we tried to construct a Markov model based on 24-h ambulatory blood pressure monitoring to simulate the disease development process of hypertension in living patients who were without stroke/myocardial infarction (MI), stroke, or MI. The longterm cost effectiveness of blood pressure reduction using Nifedipine sustained-release tablets combined with compound Apocynum tablets was further explored and compared with Nifedipine sustained-release tablets alone to provide evidence for the long-term economic effect of antihypertensive Chinese patent medicines on improving BPV.

\section{Methods \\ Model description and structure}

We developed a Markov model, using TreeAge Pro 2011 (TreeAge Software, Williamstown, MA, USA), from a Health care provider's perspective to compare 20-year timeframe costs and health benefits associated with compound Apocynum tablets and Nifedipine sustained-release tablets for patients with hypertension. Considering the long-term effects of BPV on patients with hypertension, the development and prognosis of hypertension and the literature, our Markov model was developed for six health states: alive without stroke/ MI,MI, stroke, MI, post- 
stroke, post-MI and dead. In addition, death was the absorbing state. We assumed that patients could not be in more than one state at the same time, which conformed to Markov's health states setting rules. Because hypertension is a chronic disease, its related complications take many years to manifest. Therefore, the cycle length was set to 1 year, with a time horizon of 20 years. The state transition bubble model is as follows (Fig. 1).

Considering the availability of data, our model makes the following assumptions. 1) All patients are alive without stroke/MI state when they enter the model; 2) There is a linear relationship between the incidence of the base case and time; 3) The BPV index does not change linearly with time; and 4) The cost and utility of the absorbing state was 0 . We took 1 time the GDP per capita $(\$ 9764.95)$ as the cost-effectiveness analysis threshold [23-26], and the discount rate was $5 \%$.

\section{Parameter input}

\section{Transition probabilities}

In this study, we tried to use blood pressure variability to calculate the transfer probability required by the Markov model. Studies showed in the prediction of cardiovascular disease and adverse events, nocturnal blood pressure showed better prognostic value than daytime blood pressure and 24-h blood pressure, because nocturnal blood pressure was less stimulated by physical activity, emotional stress, and the presence of the environment during the day $[27,28]$. So nocturnal blood pressure was involved as the main clinical outcomes.

Our model parameters were extracted and calculated based on published literatures (Table 1). Literature searching of the effectiveness of TCM was conducted with inclusion criteria as following: (1) patients with hypertension, (2) treatments of TCM (or combined with TCM) compared with chemical medicines, (3) using BPV as primary or secondary effectiveness indicator, (4) Randomized controlled trials. No BPV indicator, non-RCT, studies were excluded. We used "hypertension", "BPV", "TCM", RCT and other keywords to search MEDLINE (via OVID), EMBASE (via OVID), CNKI, Wan Fang, and VIP for articles published before March 2018.

Finally, we found only one RCT study. In this study, 108 patients were included in. They were divided into two groups, nifedipine sustained-release tablets $(10 \mathrm{mg}$, qd) and nifedipine sustained-release tablets $(10 \mathrm{mg}$, qd) combined with compound Apocynum tablets (2 tablets, tid) were given for 4 weeks respectively for the treatment of primary hypertension patients, and there was no difference in baseline between the two groups [29]. 24-h ambulatory blood pressure monitor were used for blood pressure monitoring before and after treatment. The results showed that nifedipine sustained-release tablets combined with compound Apocynum tablets could reduce blood pressure and the variability of blood pressure meanwhile. The Standard Deviation (SD) of systolic blood pressure was $2.99 \mathrm{mmHg}$, which could reduce the Coefficient of Variation (CV) of systolic blood pressure by 0.01 ; nifedipine sustained-release tablet group could reduce the SD by $1.87 \mathrm{mmHg}$, the CV of systolic blood pressure remained unchanged.

For the incidence of related events, we searched published RCTs, cohort studies, epidemiological literature of disease population, reviews, and national health statistical annual reports, and related statistical data, using key words "myocardial infarction", "stroke","death", "the incidence of disease" and so on. The increase in the incidence of related events caused by the change of related indicators came from the study of Tai et al. [30], which found that for every $1 \mathrm{mmHg}$ increase in the standard deviation of systolic blood pressure (SD), the incidence of stroke would increase by $2 \%$. For every $1 \%$ increase in CV of SBP, the risk of MI would increase by $5 \%$. The incidence of basic events was derived from a 5.5-year follow-up of 457 patients with hypertension in Japan.

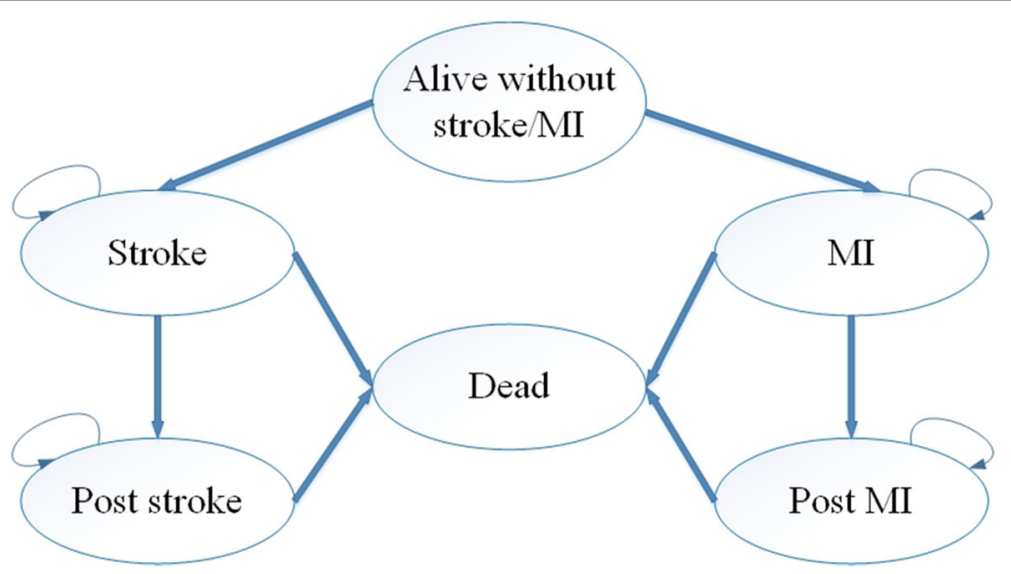

Fig. 1 Bubble Map of the Markov Model in Hypertensive Patients 
Table 1 Markov simulation parameters for BPV

\begin{tabular}{|c|c|c|c|}
\hline Items & Base Case & Range & Source \\
\hline \multicolumn{4}{|l|}{ Nocturnal Blood Pressure $\Delta S D$} \\
\hline Nifedipine & 1.87 & $1.683 \sim 2.057$ & [29] \\
\hline Compound Apocynum+Nifedipine & 2.99 & $2.691 \sim 3.289$ & [30] \\
\hline \multicolumn{4}{|l|}{ Nocturnal Blood Pressure $\Delta C V$} \\
\hline Nifedipine & 0.00 & & [29] \\
\hline Compound Apocynum+Nifedipine & 0.01 & $0.009 \sim 0.011$ & [29] \\
\hline Baseline incidence of stroke for 1 year & $1.1 \%$ & $0.01 \sim 0.012$ & [31] \\
\hline Incremental stroke incidence for 1 year & $0.320 \%$ & $0.003 \sim 0.004$ & [30] \\
\hline \multicolumn{4}{|l|}{ Incidence of stroke } \\
\hline Nifedipine & $0.460 \%$ & $0.0041 \sim 0.0051$ & \\
\hline Compound Apocynum+Nifedipine & $0.102 \%$ & $0.0009 \sim 0.0011$ & \\
\hline Baseline incidence of $\mathrm{Ml}$ for 1 year & $0.2 \%$ & $0.0018 \sim 0.0022$ & [31] \\
\hline Incremental MI incidence for 1 year & $0.811 \%$ & $0.0073 \sim 0.0089$ & [30] \\
\hline \multicolumn{4}{|l|}{ Incidence of Ml } \\
\hline Nifedipine & $0.199 \%$ & $0.0018 \sim 0.0022$ & \\
\hline Compound Apocynum+ Nifedipine & $0.193 \%$ & $0.0017 \sim 0.0021$ & \\
\hline
\end{tabular}

The results showed that 26 patients (5.69\%) had stroke and 5 patients (1.09\%) had MI. The 1-year incidence was calculated according to the probability formula [31].

The transition probabilities of stroke and MI in a single cycle of Nifedipine sustained-release tablets and $\mathrm{Ni}$ fedipine sustained-release tablets combined with compound Apocynum tablets were calculated by multiplying the decrease in the SD of blood pressure and the $\mathrm{CV}$ of a certain drug with the increase in incidence of related events caused by the change of relevant indicators and the incidence of basic events.

The probability of recurrence of and death from stroke came from a 5-year follow-up study in Singapore [32]. The results showed that the rates of recurrence and metastasis for stroke patients were $41.70 \%$ and $13.03 \%$, respectively. Data on the incidence of post-stroke and death were from Chang et al. [33]. The probability of recurrence and death after MI came from Canada's 1-year follow-up of 8493 patients with MI. The results showed that the incidence rates were $12.50 \%$ and $9.70 \%$ for recurrence and death, respectively [34]. The probability of death Post-MI comes from the study of Chiang et al. [35]. When the research time was not consistent with the time of a single cycle length, it was converted by the following probability transfer formula.

Transition probability formula : $\mathrm{t}_{\mathrm{P}}=1-(1-\mathrm{P}) 1 / \mathrm{T}$

$\mathrm{t}$ : a cycle length; $t_{\mathrm{P}}$ : transition probability per cycle length; $\mathrm{P}$ : event rate; $\mathrm{T}$ : time horizon.

\section{Utility and cost}

We used "hypertension", "myocardial infarction", "stroke", "post-stroke", "post myocardial infarction","health utility" as our keywords and searched PubMed to get the health utility of different states [36, 37]. The medicines cost of "Compound Apocynum" and "Nifedipine" collected from the YAOZHI website [38]. Cost of hospitalization for patients in different states collected from The Health Statistical Yearbook of China in 2013 [39] and a study by Chan et al. [40]. In this study the cost was calculated on a yearly basis (Table 2). All searches were by March 2018.

\section{Sensitivity analysis}

A one-way sensitivity analysis and a probability sensitivity analysis (PSA) were used to verify the robustness of the results. For the one-way sensitivity analysis several factors that had the greatest impact on the results were chosen, including cost, utility, transfer probability that fluctuated by $10 \%[41,42]$ and discount rate that fluctuated by $1 \% \sim 8 \%$ [23]. Combined with the source literature for the model parameters, the distribution method of cost was Gamma, and the distribution method of utility and transfer probability was Beta.

\section{Results}

\section{Base case analysis}

The Markov model was used for a cost-effectiveness analysis of the two treatments for hypertension (Table 3) in TreeAge Pro 2011. The cumulative cost after 20 years was $\$ 1739.87$, and the health output was 12.69 QALYs in the compound Apocynum+Nifedipine group; the cumulative cost after 20 years was $\$ 1095.73$, and the health output 
Table 2 Summary of inputs used in the base-case model

\begin{tabular}{|c|c|c|c|}
\hline Items & Base Case & Range & Source \\
\hline Baseline age & 67.5 & $60 \sim 75$ & MF Ju [29] \\
\hline \multicolumn{4}{|l|}{ Transition probability } \\
\hline \multicolumn{4}{|l|}{ Alive without stroke/Ml $\rightarrow$ stroke } \\
\hline Nifedipine & $0.460 \%$ & $\begin{array}{l}0.0041 \sim 0.0051 \\
0.0009 \sim 0.0011\end{array}$ & [29-31] \\
\hline Compound Apocynum+ Nifedipine Levamlodipine & $0.102 \%$ & $0.0009 \sim 0.0011$ & [29-31] \\
\hline \multicolumn{4}{|l|}{ Alive without stroke/Ml $\rightarrow$ stroke } \\
\hline Nifedipine & $0.199 \%$ & $0.0018 \sim 0.0022$ & [29-31] \\
\hline Compound Apocynum+ Nifedipine Levamlodipine & $0.193 \%$ & $0.0017 \sim 0.0021$ & [29-31] \\
\hline Stroke $\rightarrow$ Stroke & 41.7\%(5 year) & $0.3753 \sim 0.4587$ & {$[32]$} \\
\hline Post-stroke $\rightarrow$ Death & $25.6 \%$ (4 year) & $0.2304 \sim 0.2816$ & [33] \\
\hline Stroke $\rightarrow$ Death & $13.03 \%$ (5 year) & $0.1172 \sim 0.1433$ & [33] \\
\hline $\mathrm{Ml} \rightarrow \mathrm{Ml}$ & $12.50 \%$ & $0.1125 \sim 0.1375$ & [34] \\
\hline Post-Ml $\rightarrow$ Death & $6.10 \%$ & $0.0549 \sim 0.0671$ & [35] \\
\hline $\mathrm{Ml} \rightarrow$ Death & $9.70 \%$ & $0.0873 \sim 0.1067$ & [34] \\
\hline \multicolumn{4}{|l|}{ Utility } \\
\hline Alive without stroke & 0.98 & $0.882 \sim 1$ & {$[36]$} \\
\hline Stroke & 0.5 & $0.45 \sim 0.55$ & {$[37]$} \\
\hline $\mathrm{Ml}$ & 0.70 & $0.63 \sim 0.77$ & {$[37]$} \\
\hline Post-stroke & 0.63 & $0.567 \sim 0.693$ & [37] \\
\hline Post-Ml & 0.8 & $0.72 \sim 0.88$ & [37] \\
\hline \multicolumn{4}{|l|}{ Cost (USD/per year) } \\
\hline Nifedipine drug costs & 16.31 & $14.68 \sim 17.95$ & [38] \\
\hline Compound Apocynum+Nifedipine drug costs ii & 102.42 & $92.18 \sim 112.66$ & [38] \\
\hline MI (in hospital) & 2538.01 & $2284.26 \sim 2791.87$ & [39] \\
\hline Stroke (in hospital) & 1843.86 & $1659.56 \sim 2028.35$ & [39] \\
\hline Post-stroke & 1692.15 & $1522.93 \sim 1861.36$ & {$[40]$} \\
\hline Post-Ml & $20,141.84$ & $1837.66 \sim 2246.03$ & [40] \\
\hline
\end{tabular}

was 12.50 QALYs in the Nifedipine group. The incremental cost-effectiveness analysis showed that the ICER of compound Apocynum tablets combined with Nifedipine sustained-release tablets was $\$ 3390.23$ compared with $\mathrm{Ni}$ fedipine sustained-release tablets, which was lower than the threshold (1 GDP per capita $=\$ 9764.95$ ).

\section{Sensitivity analysis}

\section{One-way sensitivity analysis}

We carried out a one-way sensitivity analysis. A tornado diagram was developed to illustrate the sensitivity of ICER to changes in key parameters (Fig. 2). The five most sensitive parameters in the cost-effectiveness analysis were the transition probability from alive without stroke/MI to stroke in Nifedipine, the cost of compound Apocynum+ Nifedipine, transition probability from alive without stroke/MI to MI in Nifedipine group, transition probability from alive without stroke/MI to MI in the compound Apocynum+Nifedipine group, and utility of post-stroke. The one-way sensitivity analyses of the top five factors have shown that the economic results are still stable, in other words, the ICER value is still at the threshold after the factor fluctuates by $10 \%$. The one-way sensitivity analyses results were robust (Table 4).

Table 3 Base case results from the cost-effectiveness analyses

\begin{tabular}{lllll}
\hline Treatments & Cost (USD) & QALYs & CER & ICER \\
\hline Compound Apocynum+Nifedipine & 1739.87 & 12.69 & 137.11 & 3390.23 \\
Nifedipine & 1095.73 & 12.50 & 87.66 \\
\hline
\end{tabular}




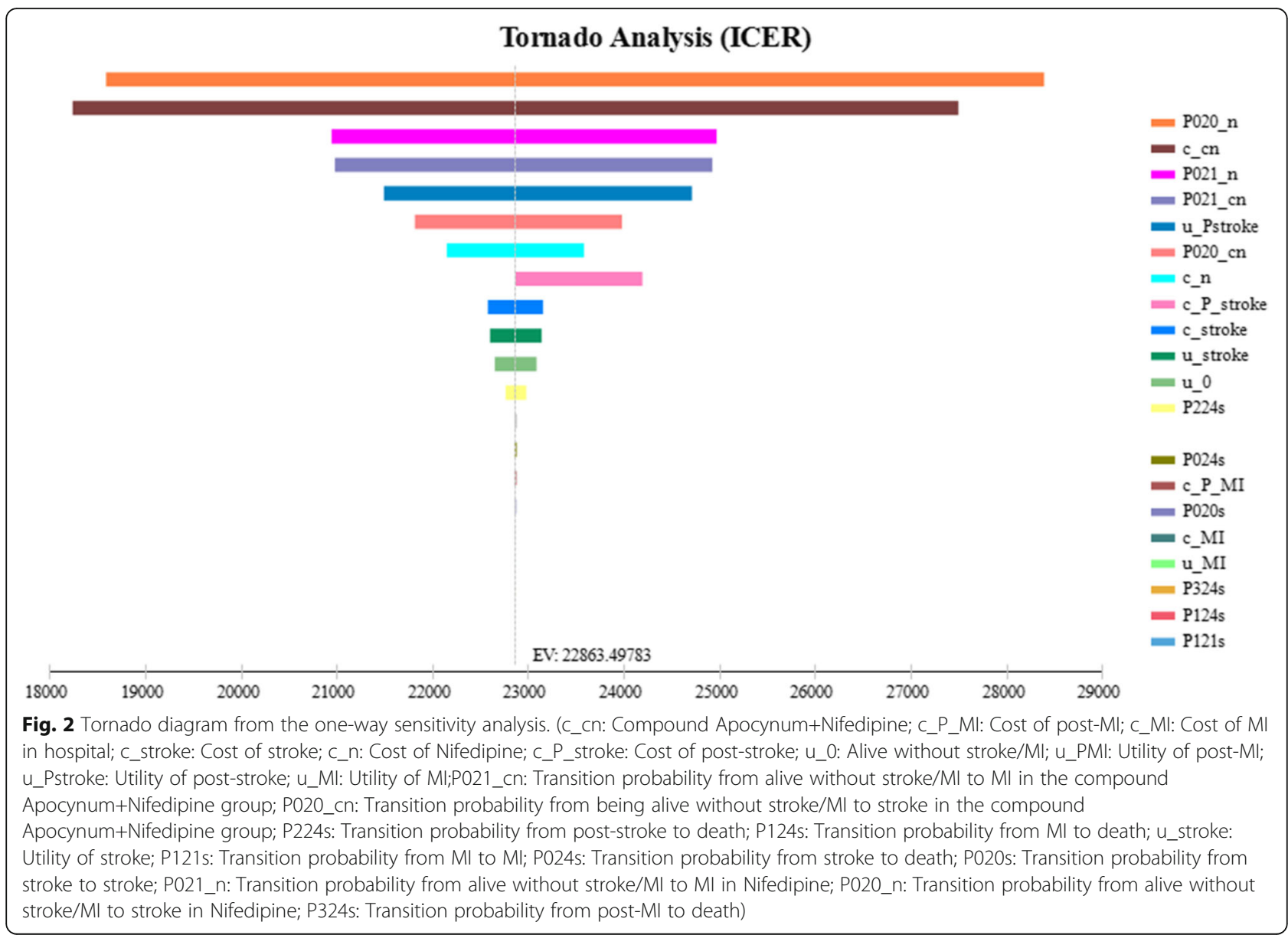

\section{Probabilistic sensitivity analysis}

The scatter plot of the PSA results (Fig. 3) shows that there was an $84.5 \%$ chance of the compound Apocynum+ Nifedipine treatment strategy being cost-saving compared with Nifedipine. The shape of the scatter plot indicates a linear relationship between efficacy and cost; that is, the greater the number of QALYs obtained, the lower the incremental cost. A cost-effectiveness acceptability curve $(\mathrm{CEAC})$ illustrates the probability that an intervention is more cost-effective compared with the alternative intervention(s). For different WTP thresholds, different strategies are optimal. With respect to WTP, as the value varied from $\$ 0$ to $\$ 9764.95(59,201 \mathrm{RMB})$, the acceptable proportion of the compound Apocynum+Nifedipine group increased, while the acceptable percentage for the Nifedipine group decreased (Fig. 4).

\section{Discussion}

Previous systematic review demonstrated that there is a relative lack of cost-effectiveness research in TCMs [43]. In this study, the Markov model was constructed based on BPV to simulate the long-term effects of TCMs on the health status of hypertensive patients. This study contains reference values for future long-term economic evaluations of antihypertensive TCMs. The evaluation results can also serve as a reference for the diagnosis and treatment of clinical primary hypertension patients.

The choice of research perspective in economic evaluation determines the measurement range of cost. This study selected the Health Care Provider's Perspective. The results show that the combination of compound Apocynum tablets and Nifedipine sustained-release tablets was a cost-effective strategy in the Health Care Provider's Perspective. In other words, it was economical to use TCMs combined with chemical drugs in Chinese medical institutions to treat hypertension patients. The different drug utilization patterns were impacted our results, such as combined with different Chemical antihypertensive drugs. However, pharmacoeconomic assessments were based on data from clinical trials or real-world data, and further TCMs clinical trials and real-world studies were recommended.

Although reducing hypertensive variability is an advantage of antihypertensive TCMs, there are still few clinical studies in China, and the existing studies had a lot limitations and were small in scale. Chen et al. [44] proved that the combination of Tianma Gouteng Decoction and 


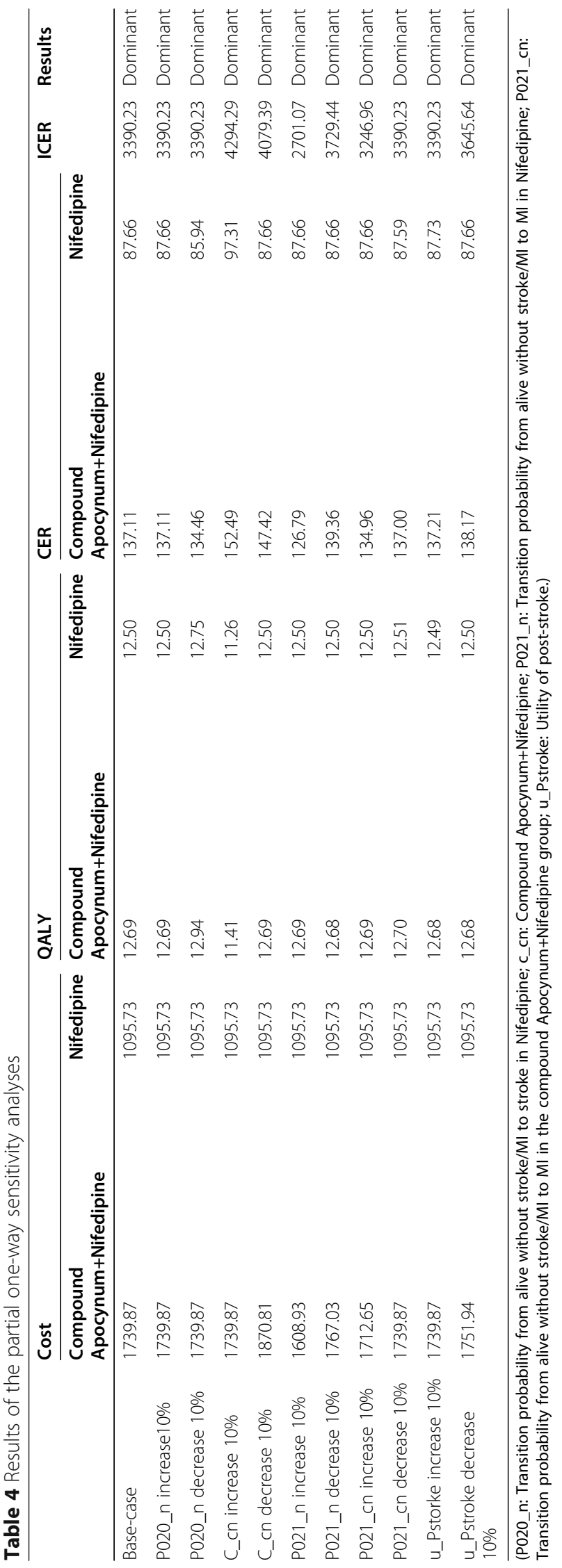


Incremental Cost-Effectiveness, nife dipine sustained-rele ase tablets combined with compound apocynum $v$. sustained-rele ase tablets

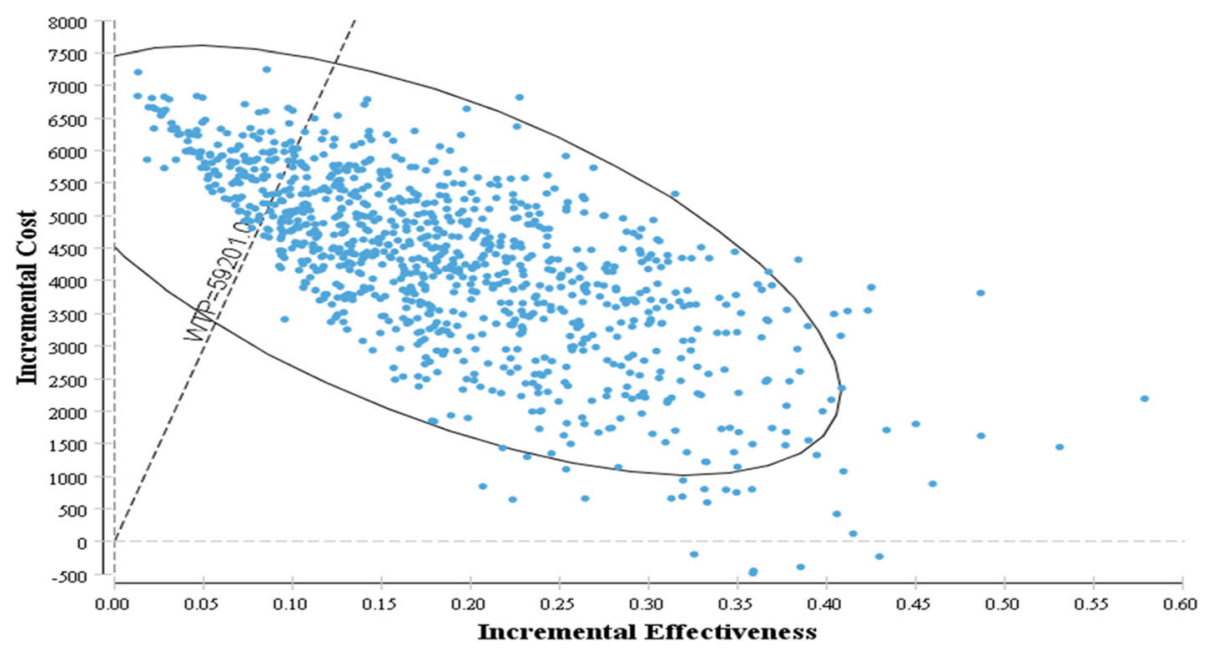

Fig. 3 PSA Scatter plot of the incremental cost/QALY ratio

amlodipine besylate tablets could reduce the 24-h average systolic and diastolic blood pressure of patients. Fang et al. [45] found that benazepril combined with antelope horn capsules could reduce morning blood pressure. Wang et al. [46] found that Songling Xuemaikang capsules combined with amlodipine besylate tablets could reduce the standard deviation of blood pressure in hypertension patients during the day and night, but the study lacked the corresponding data for mean blood pressure. Generally, most studies only describe the average blood pressure level in daytime, at night and over 24 h [47]. However, only one study [29] reported the SD and CV of blood pressure which are the most commonly used indicators of BPV. This study only compared the efficacy of chemical drugs alone with that of chemical drugs combined with TCMs. It did not compare a chemical drugs directly with a TCM used to reduce blood pressure. BPV affects the occurrence of stroke and MI. Some studies have found that BPV is closely related to kidney damage $[11,12]$. When $\mathrm{BPV}$ increases, it may be due to an increase in microvascular resistance and small vessel resistance, which causes high blood pressure, high perfusion and high

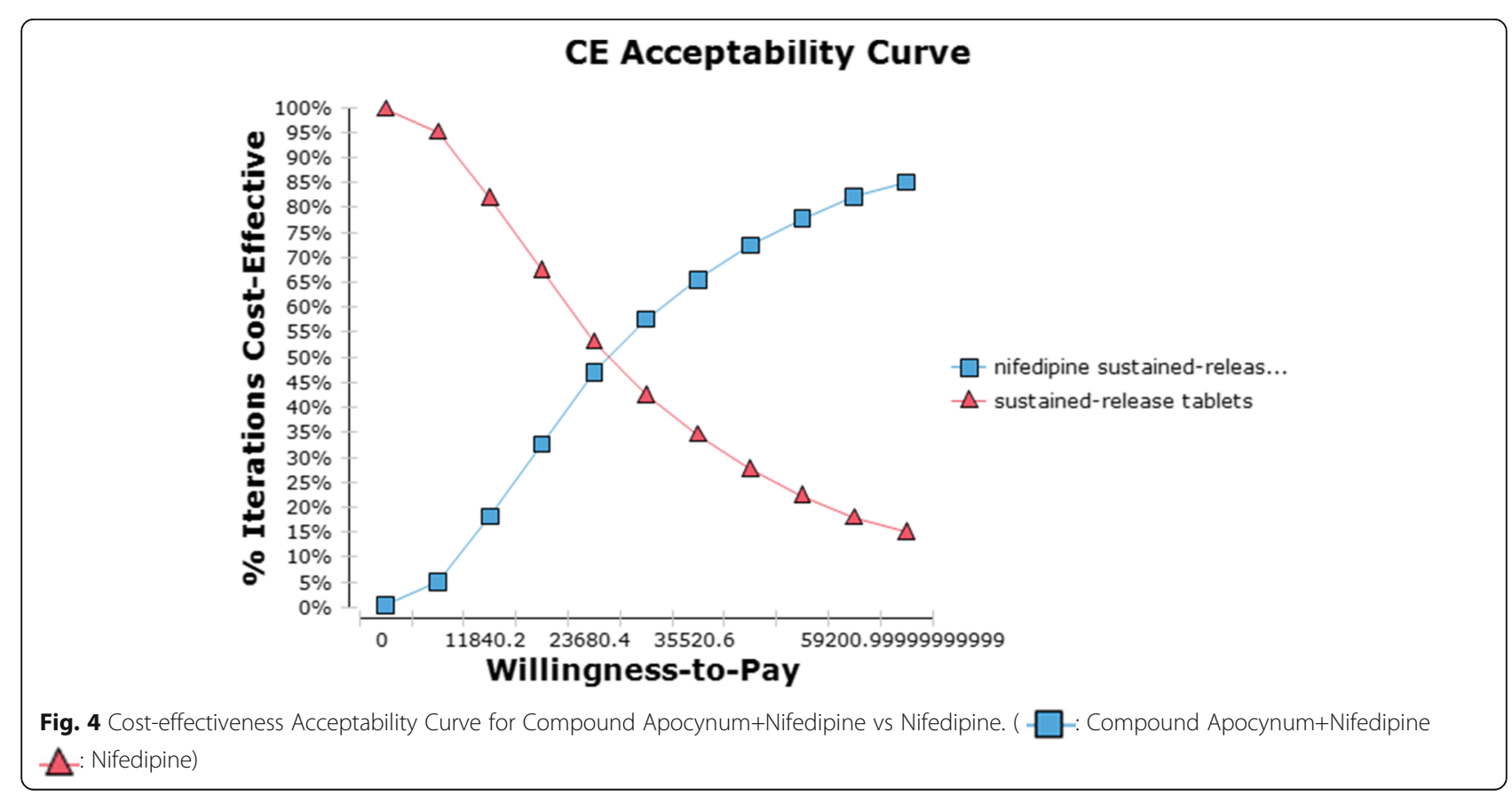


filtration. However, there is no data to quantify the relationship between BPV and renal damage, so this relationship has not been included in this study. Therefore, relevant empirical research to verify and improve the construction of this study is recommended to simulate longterm disease development in hypertensive patients.

This study had several limitations. First, in this study, the parameters such as efficacy and disease state transition probability were from the limited literature available at present. For example, the clinical efficacy data of two drug treatment schemes were from a small sample of short-term RCT, and the incidence of stroke caused by blood pressure variability was from the international literature rather than the Chinese population. All of these brought certain uncertainty to the calculation results of the model. And we needed more data from large samples of long-term RCT with blood pressure variability as an indicator and epidemiological studies based on the relationship between blood pressure variability and stroke, MI, etc. in Chinese population to update our study. Second, the health utility values were one of the key parameters in cost-effectiveness analysis, however, we didn't found study about the utility values of Chinese population. Therefore, it is suggested to carry out utility measurement based on Chinese population in the future. Third, we did not fully explore other therapeutic strategies for TCMs combined with Antihypertensive chemical drugs. This paper has presented a long-term economic evaluation method of TCM combined with chemical drugs in the treatment of hypertension. Therefore, it was suggested to compare the economics of more treatment strategies in future studies.

\section{Conclusions}

The pharmacoeconomic results for Nifedipine sustainedrelease tablets combined with compoundApocynum compared with Nifedipine sustained-release tablets alone indicated that the total cost of compound Apocynum+ Nifedipine after 20 years was $\$ 1739.87$ and the health output was 12.69 QALYs; the cumulative cost of Nifedipine for 20 cycles was $\$ 1095.73$, and the health output was 12.50 QALYs. The results of the incremental cost-effectiveness analysis are presented. The ICER of compound Apocynum tablets and Nifedipine sustained-release tablets was lower than the threshold value, so it is economical.

\section{Abbreviations}

TCMs: Traditional Chinese medicines; QALYs: Quality-adjusted life-years; CVD: Cardiovascular; BPV: Blood pressure variability; SD: Standard deviations; CV: Coefficient of variations; SBP: Systolic blood pressure; DBP: Diastolic blood pressure; MI: Myocardial infarction; PSA: Probabilistic sensitivity analysis; WTP: Willingness to pay

\section{Authors' contributions}

$\mathrm{MH}$ has participated on the design, has revised text, and made the statistical analyses, QBL was the instigator of the concept and has contributed to the methodology of this study, QX has participated on the design and in the data collection and written the text, NY has participated on the design and in the data collection and written the text, SF and JFG have participated on revised text. All authors read and approved the final manuscript.

\section{Funding}

This research has been supported by National Key R\&D Program of China (Grant No. 2019YFC1709804), Sichuan Administration of Traditional Chinese Medicine (Project Number: 2018ZC004), Innovation and Talent Recruiting Program for Higher Education (The 111 Project; Project Number: B18035).

\section{Availability of data and materials}

All data generated or analysed during this study are included in this published article [[1] Ju MF,Wang H, Hong R, et.al. Observation on curative effect of Compound Apocynum tablets in the treatment of senile essential hypertension [J]. J Chengde Med Coll. 2014(06): 532-533.

[2] Tai C, Sun Y, Dai N, et al. Prognostic significance of visit-to-visit systolic blood pressure variability: a meta-analysis of 77,299 patients [J]. J Clin Hypertens (Greenwich). 2015, 17(2): 107-115.

[3] Eguchi K, Hoshide S, Schwartz J E, et al. Visit-to-visit and ambulatory blood pressure variability as predictors of incident cardiovascular events in patients with hypertension [J]. Am J Hypertens. 2012, 25(9): 962-968.

[4] Sun Y, Lee S H, Heng B H, et al. 5-year survival and rehospitalization due to stroke recurrence among patients with hemorrhagic or ischemic strokes in Singapore [J]. BMC Neurol. 2013, 13: 133.

[5] Chang K C, Lee H C, Tseng M C, et al. Three-year survival after first-ever ischemic stroke is predicted by initial stroke severity: A hospital-based study

[J]. Clin Neurol Neurosurg. 2010, 112(4): 296-301.

[6] Tangri N, Ferguson T W, Whitlock R H, et al. Long term health outcomes in patients with a history of myocardial infarction: A population based cohort study [J]. PLoS One. 2017, 12(7): e180010.

[7] Chiang F T, Shyu K G, Wu C J, et al. Predictors of 1-year outcomes in the Taiwan Acute Coronary Syndrome Full Spectrum Registry [J]. J Formos Med Assoc. 2014, 113(11): 794-802.

[8] Stein J D, Brown G C, Brown M M, et al. The quality of life of patients with hypertension [J]. J Clin Hypertens (Greenwich). 2002, 4(3): 181-188.

[9] Ara R, Tumur I, Pandor A, et al. Ezetimibe for the treatment of hypercholesterolaemia: a systematic review and economic evaluation [J]. Health Technol Assess. 2008, 12(21): 1-212.], some data were collected from YAOZHI website [https://www.yaozh.com/] and The Health Statistical Yearbook of China in 2013.

\section{Ethics approval and consent to participate}

Not applicable.

\section{Consent for publication \\ Not applicable.}

\section{Competing interests}

The authors declare that they have no competing interests.

\section{Author details}

${ }^{1}$ West China School of Pharmacy Sichuan University, 17, Renmin South Road, 3rd Section, Chengdu 610041, Sichuan, China. ${ }^{2}$ Division of Pharmacy Practice and Administrative Sciences, College of Pharmacy, University of Cincinnati Medical Center, Cincinnati, OH, USA. ${ }^{3}$ Department of Pharmacology, School of Pharmaceutical Science, Hainan Medical University, Haikou, Hainan, China.

Received: 8 October 2019 Accepted: 17 September 2020

Published online: 05 November 2020

\section{References}

1. Yang G, Wang Y, Zeng Y, et al. Rapid health transition in China, 1990-2010: findings from the global burden of disease study 2010. Lancet. 2013; 381(9882):1987-2015.

2. Hua Q, Fan L, Li J, et al. China experts consensus on the managements of hypertension in the very old people. Chin J Cardiovasc Med. 2015;06:401-9. https://doi.org/10.3969/j.issn.1007-5410.2015.06.001. 
3. Stevens W, Peneva D, Li JZ, et al. Estimating the future burden of cardiovascular disease and the value of lipid and blood pressure contro therapies in China. BMC Health Serv Res. 2016;16:175.

4. Hua SH, Liu GE, Sun LH, et al. The effect of overweight and obesity on the burden of medical expenses in patients with hypertension. Health Econ Res. 2017;10:27-9.

5. Yikona Jl, Wallis EJ, Ramsay LE, et al. Coronary and cardiovascular risk estimation in uncomplicated mild hypertension. A comparison of risk assessment methods. J Hypertens. 2002;20(11):2173-82.

6. Parati G, Ochoa JE, Lombardi C, et al. Assessment and management of blood-pressure variability. Nat Rev Cardiol. 2013;10(3):143-55.

7. Verdecchia P, Angeli F, Gattobigio R, et al. Impact of blood pressure variability on cardiac and cerebrovascular complications in hypertension. Am J Hypertens. 2007;20(2):154-61.

8. Stolarz K, Staessen JA, O'Brien ET. Night-time blood pressure: dipping into the future? J Hypertens. 2002;20(11):2131-3.

9. Rothwell PM, Howard SC, Dolan E, et al. Effects of beta blockers and calcium-channel blockers on within-individual variability in blood pressure and risk of stroke. Lancet Neurol. 2010;9(5):469-80.

10. Rothwell PM, Howard SC, Dolan E, et al. Prognostic significance of visit-tovisit variability, maximum systolic blood pressure, and episodic hypertension. Lancet. 2010;375(9718):895-905.

11. Luo JF, Zhou ZP, Xu ZJ. Review on blood pressure variability in traditional Chinese medicine. J Pract Trad Chin Inter Med. 2016;10:89-92.

12. Meng LL, Lu JF, Wang SF. Advances in the study of Chinese medicine intervention on blood pressure variability. Trad Chin Med Res. 2015;04:68-70.

13. Wu C, Zhang J, Zhao Y, Chen J, Liu Y. Chinese herbal medicine bushen qinggan formula for blood pressure variability and endothelial injury in hypertensive patients: a randomized controlled pilot clinical trial. Evid Based Complement Alternat Med. 2014;2014:804171. https://doi.org/10.1155/2014/804171.

14. Chen YY, Chen J, Zhang JC, Chen KJ. Effect of qingxuan granule (清眩颗粒) on blood pressure variability of hypertensive patients with and without obstructive sleep apnea. Chin J Integr Med. 2013.

15. Zhu H, Lu S, Su W, Gong S, Zhang Z, Li P. Effect of Liandouqingmai recipe on life quality and vascular endothelial injury in patients with coronary heart disease. J Tradit Chin Med. 2012;32(4):529-33.

16. Xinyu $C$, Linglong $Y$, Zixuan $L$, et al. Meta-analysis of Banxia Baizhu Tianma decoction in treatment of primary hypertension. Liaoning J Tradit Chin Med. 2014:41(02):196-9.

17. Yixin G, Xinlin C, Zhenwen Q, et al. Meta-analysis and systematic reviews of Liuweidihuang pills combined with Western medicine on hypertension. J Emerg Tradit Chin Med. 2013;22(02):189-91.

18. Expert Committee on rational drug use of national health and Family Planning Commission, hypertension Committee of Chinese Medical Association. Guidelines for rational use of hypertension (2nd Edition) [J]. Chin J Med Front (Electronic Edition). 2017;(7).

19. Chinese expert consensus document on antihypertensivetherapy with single-pill combination of Expert group, Chinese Society of Cardiology, China Association of Gerontology and Geriatrics. Chinese expert consensus document on antihypertensive therapy with single-pill combination. Chin J Cardiol. 2012;20(7):624-8

20. Kim D, Yokozawa T, Hattori M, et al. Effects of aqueous extracts ofApocynum leaves on spontaneously hypertensive, renal hypertensive and NaCl-fed-hypertensive rats. J Ethnopharmacol. 2000;72(1-2):53-9.

21. Zeng B, Tian L, Yan X. Advances in Pharmacological Action and Modern Application ofApocynum in Xinjiang. Chin J Ethnomed Ethnopharm. 2009;(02):11-3.

22. Cui LL, Lv JH. Modern pharmacological study and clinical application ofApocynum. Chin Med Modern Distance Educ China. 2009;06:187.

23. Chinese pharmacoeconomics evaluation guidelines, research group, Guoen $\mathrm{L}$, Shanlian H, Jiuhong W. China Guidelines for PharmacoeconomicEvaluations (2020 Edition)[M]. Beijing: China Market Press; 2020.

24. Yang SC, Lai WW, Hsu JC, Su WC, Wang JD. Comparative effectiveness and cost-effectiveness of three first-line EGFR-tyrosine kinaseinhibitors: Analysis of real-world data in a tertiary hospital in Taiwan. PLoS One. 2020;15(4): e0231413. https://doi.org/10.1371/journal.pone.0231413.

25. Yang J, Yan $\mathrm{H}$, Feng $\mathrm{L}, \mathrm{Yu} \mathrm{H}$. Cost-effectiveness of potential government fully-funded influenza vaccination in population with diabetes in China. Zhonghua Yu Fang Yi Xue Za Zhi. 2019;53:1000-6. https://doi.org/10.3760/ cma.j.jissn.0253-9624.2019.10.009.

26. Chan S, Lim YH, Subongkot S, et al. Cost-effectiveness analysis of olanzapine-containing antiemetic therapy for managing highly emetogenic chemotherapy in Southeast Asia: a multinational study. Support Care Cancer. 2019:27(3):1109-19. https://doi.org/10.1007/s00520-018-4400-1.

27. Sega R, Facchetti R, Bombelli $M$, et al. Prognostic value of ambulatory and home blood pressures compared with office blood pressure in the general population: follow-up results from the Pressioni Arteriose Monitorate e Loro Associazioni (PAMELA) study. Circulation. 2005;111(14):1777-83.

28. Dolan E, Stanton A, Thijs L, et al. Superiority of ambulatory over clinic blood pressure measurement in predicting mortality: the Dublin outcome study. Hypertension. 2005;46(1):156-61.

29. Ju MF, Wang $H$, Hong $R$, et al. Observation on curative effect of Compound Apocynum tablets in the treatment of senile essential hypertension. $J$ Chengde Med Coll. 2014;(06):532-3.

30. Tai $C$, Sun $Y$, Dai N, et al. Prognostic significance of visit-to-visit systolic blood pressure variability: a meta-analysis of 77,299 patients. J Clin Hypertens (Greenwich). 2015;17(2):107-15.

31. Eguchi K, Hoshide S, Schwartz JE, et al. Visit-to-visit and ambulatory blood pressure variability as predictors of incident cardiovascular events in patients with hypertension. Am J Hypertens. 2012;25(9):962-8.

32. Sun $\mathrm{Y}$, Lee $\mathrm{SH}$, Heng BH, et al. 5-year survival and rehospitalization due to stroke recurrence among patients with hemorrhagic or ischemic strokes in Singapore. BMC Neurol. 2013;13:133.

33. Chang $\mathrm{KC}$, Lee $\mathrm{HC}$, Tseng $\mathrm{MC}$, et al. Three-year survival after first-ever ischemic stroke is predicted by initial stroke severity: a hospital-based study. Clin Neurol Neurosurg. 2010;112(4):296-301.

34. Tangri N, Ferguson TW, Whitlock RH, et al. Long term health outcomes in patients with a history of myocardial infarction: a population based cohort study. PLoS One. 2017;12(7):e180010.

35. Chiang FT, Shyu KG, Wu CJ, et al. Predictors of 1-year outcomes in the Taiwan acute coronary syndrome full Spectrum registry. J Formos Med Assoc. 2014;113(11):794-802.

36. Stein JD, Brown GC, Brown MM, et al. The quality of life of patients with hypertension. J Clin Hypertens (Greenwich). 2002;4(3):181-8.

37. Ara R, Tumur I, Pandor A, et al. Ezetimibe for the treatment of hypercholesterolaemia: a systematic review and economic evaluation. Health Technol Assess. 2008;12(21):1-212.

38. Yaozhi.net.[DB/OL]. http://www.yaozh.com/. Accessed Mar 2018

39. China Health and Family Planning Commission, China Health Statistics Yearbook 2013[M]. Beijing: China Union Medical University Press; [EB/OL]. https://data.cnki.net/area/Yearbook/Single/N2014010012?z=D09.

40. Chan L, Chen CH, Hwang JJ, Yeh SJ, Shyu KG, Lin RT, Li YH, Liu LZ, Li JZ, Shau WY, Weng TC. Cost-effectiveness of amlodipine compared with valsartan in preventing stroke and myocardial infarction among hypertensive patients in Taiwan. Int J Gen Med. 2016;9:175-82. https://doi.org/10.2147/JJGM.S102095.

41. Yang F, Fu YY, Xiao DM, Xuan JW. Cost effectiveness analysis of sulodexide in the treatment of patients with chronic venous insufficiency. Chin J Ration Drug Use. 2020;17(04):36-43.

42. Amirsadri M, Hassani A. Cost-effectiveness and cost-utility analysis of OTC use of simvastatin $10 \mathrm{mg}$ for the primary prevention of myocardial infarction in Iranian men. Daru. 2015;23:56. Published 2015 Dec 30. https:// doi.org/10.1186/s40199-015-0129-2.

43. Zhang F, Kong LL, Zhang YY, et al. Evaluation of Impact on Health-Related Quality of Life and Cost Effectiveness of Traditional Chinese Medicine: A Systematic Review of Randomized Clinical Trials. J Altern Complement Med. 2012;18(12):1108-20.

44. Chen ZJ. Effect of Tianma Gouteng decoction on blood pressure variability in hypertensive patients with hyperactivity of liver Yang. New Chin Med. 2014;03:52-4.

45. Fang XJ, Qian BQ. Effect of Lingyangjiao capsule on blood pressure variability, pulse pressure and left ventricular quality in elderly patients with simple systolic hypertension. Chin J Tradit Chin Med. 2010;06:936-8.

46. Wang FQ. Observation on the efficacy of Songling Xuemaikang combined with amlodipine in reducing blood pressure variability in patients with essential hypertension. Jilin J Tradit Chin Med. 2011;31(2):149-50.

47. Kikuya M, Hozawa A, Ohokubo T, et al. Prognostic significance of blood pressure and heart rate variabilities: the Ohasama study. Hypertension. 2000; 36(5):901-6.

\section{Publisher's Note}

Springer Nature remains neutral with regard to jurisdictional claims in published maps and institutional affiliations. 